\title{
Efecto del biofilm de dos cepas bacterianas nativas sobre el asentamiento de larvas de Argopecten purpuratus
}

\author{
Effect of the biofilm of two native bacterial strains on the settlement of \\ Argopecten purpuratus larvae
}

\author{
Charles Roque ${ }^{1}$, Oscar Mendoza ${ }^{1,2}$
}

\section{Resumen}

El objetivo de la presente investigación fue aislar, seleccionar y caracterizar genéticamente bacterias nativas de Argopecten purpuratus que, a través de un biofilm, estimulen su asentamiento larval. Conociendo que el asentamiento larval es el principal problema que afronta la reproducción en laboratorio de este molusco, se utilizó un biofilm bacteriano para mejorar porcentualmente la fijación larval. Se aislaron cepas bacterianas nativas del cultivo de $A$. purpuratus y se caracterizaron taxonómicamente a partir del análisis de las secuencias parciales del gen 16S rARN, amplificadas mediante PCR a cada una de las muestras de ADN extraídas de las cepas bacterianas aisladas. Al analizar las secuencias se identificó a nivel de género tres cepas bacterianas; Oceanobacillus, Bacillus y Pseudomonas. Además, se avaluó la eficiencia de fijación de larvas de A. purpuratus en los biofilms formados por las cepas Oceanobacillus y Bacillus logrando una fijación de 12 y $14 \%$, en tanto que al estar asociadas fue de $37 \%$. Se concluye que la fijación larvaria de A. purpuratus mejora con el biofilm bacteriano compuesto por Oceanobacillus y Bacillus, en comparación con el control, sin uso de bacterias.

Palabras clave: asentamiento larval, Argopecten purpuratus, biofilm, Pseudomonas, Oceanobacillus, Bacillus

\footnotetext{
${ }^{1}$ Facultad de Ingeniería Pesquera y Ciencias del Mar, Universidad Nacional de Tumbes, Perú

${ }^{2}$ E-mail: oscarmendoza7@gmail.com
}

Recibido: 13 de mayo de 2021

Aceptado para publicación: 15 de noviembre de 2021

Publicado: 22 de diciembre de 2021

CLos autores. Este artículo es publicado por la Rev Inv Vet Perú de la Facultad de Medicina Veterinaria, Universidad Nacional Mayor de San Marcos. Este es un artículo de acceso abierto, distribuido bajo los términos de la licencia Creative Commons Atribución 4.0 Internacional (CC BY 4.0) [https:// creativecommons.org/licenses/by/4.0/deed.es] que permite el uso, distribución y reproducción en cualquier medio, siempre que la obra original sea debidamente citada de su fuente original 
The aim of this study was to isolate, select and genetically characterize native Argopecten purpuratus bacteria that, through a biofilm, stimulate their larval settlement. Knowing that larval settlement is the main problem faced by the laboratory reproduction of this mollusk, a bacterial biofilm was used to improve the larval fixation percentage. Native bacterial strains were isolated from the A. purpuratus culture and taxonomically characterized from the analysis of the partial sequences of the $16 \mathrm{~S}$ rRNA gene, amplified by PCR to each of the DNA samples extracted from the isolated bacterial strains. When analyzing the sequences, three bacterial strains were identified at the genus level: Oceanobacillus, Bacillus, and Pseudomonas. In addition, the fixation efficiency of $A$. purpuratus larvae was evaluated in the biofilms formed by the Oceanobacillus and Bacillus strains, achieving a fixation of 12 and $14 \%$, while being associated was $37 \%$. It is concluded that the larval fixation of $A$. purpuratus improves with the bacterial biofilm composed of Oceanobacillus and Bacillus, compared to the control, without the use of bacteria.

Key words: settlement, Argopecten purpuratus, biofilm, Pseudomonas, Oceanobacillus, Bacillus

\section{INTRODUCCIÓN}

Argopecten purpuratus (Lamarck, 1819) es un molusco bivalvo que se distribuye entre Paita, Perú $\left(5^{\circ} \mathrm{S}, 81^{\circ} \mathrm{O}\right)$ a Valparaíso, Chile $\left(33^{\circ} \mathrm{S}, 71^{\circ} \mathrm{O}\right)$ (Avendaño y Cantillánez, 2008); especie hermafrodita funcional cuyas gónadas, tanto femenina como masculina, maduran simultáneamente. La primera madurez gonadal se estima a los $65 \mathrm{~mm}$ de longitud de valva, entre 10 a 12 meses de edad (Pazos et al., 1993). Desovan entre 1 a 10 millones de óvulos (Bermúdez et al., 2004; FAO, 2006).

$\mathrm{Su}$ ciclo de vida se inicia $24 \mathrm{~h}$ pos-fecundación empezando con una etapa larval plantónica, la que puede durar entre 18 a 22 días; una larva trocófora de forma ovalada seguida de una larva umbonada y una última fase larva pediveliger (FAO, 2006). Cuando la larva mide entre 200 a $330 \mu \mathrm{m}$ se inicia la fijación, asentándose a un sustrato adecuado, comenzando su existencia bentónica, siendo el inicio de esta etapa un momento crítico de no encontrar un sustrato o estimulo adecuado en donde fijarse (Bonar et al., 1990; Tapia et al., 1993).

Las señales químicas son fundamentales para desencadenar la respuesta del asentamiento larval, inductores artificiales se asocian a sustancias neurotransmisoras y sus precursores, sustancias químicas tales como potasio, L-3-3,4-dihidroxifenilalanina, acido raminobutírico, colina y sus derivados son inductores naturales que se han caracterizado a partir de la respuesta del asentamiento, como consecuencia de la presencia de los sustratos naturales, tales como: individuos coespecíficos, biofilms microbianos y especies presa (Rodríguez et al., 1992). Se define como biofilm o biopelícula a una comunidad de microorganismos que crecen embebidos en una matriz de exopolisacáridos y adheridos a una superficie inerte o un tejido vivo (Donlan, 2002). Los microorganismos colonizadores son muy variados (microalgas, hongos, protozoos y bacterias), siendo las bacterias las dominantes (Sutherland, 2001), y en menor número se encuentran otras macro- 
moléculas como proteínas, ADN y productos diversos procedentes de la lisis bacteriana (Branda et al., 2005).

Los factores bióticos como los biofilms monoespecíficos o multiespecíficos pueden inhibir o incentivar la fijación de larvas de moluscos sobre un substrato (Yang et al., 2013). La respuesta de asentamiento a estos biofilms se genera, al parecer, por la presencia de polisacáridos o glicoproteínas extracelulares unidos a la pared bacteriana (Hadfield, 1986), o bien por compuestos solubles liberados por los biofilms (Bonar et al., 1990). Inductores relacionados a biofilms microbianos son importantes en el asentamiento larval de muchos invertebrados marinos bentónicos, habiéndose observado inducción tanto por biofilms de diatomeas y de cianobacterias (Morse A y Morse D, 1984).

Varios investigadores afirman que las larvas de moluscos se asientan en respuesta a un tipo específico de biofilm formado sobre un sustrato (Fitt et al., 1990; Tamburri et al., 1992; Wainman et al., 1996); en cambio otras pueden exhibir una variedad de respuestas frente a la presencia o ausencia del biofilm (Maki et al., 1992). Por su parte, Wolfaart et al. (1994) refieren que los mayores porcentajes de asentamientos inducidos por un biofilm se producen después de su estabilización entre los 14 a 21 días de iniciada su formación. Los microorganismos a menudo construyen y viven dentro de comunidades multicelulares asociadas a superficies conocidas como biopelículas o biofilms. La estructura precisa, química y fisiología de la todas las biopelículas varían con la naturaleza de los microorganismos residentes y medio ambiente local (Branda et al., 2005), y secuestran nutrientes originando estrategias de supervivencia bajo condiciones oligotróficas (Decho, 2000).

Riquelme et al. (1995), utilizando gónadas de reproductores de A. purpuratus, aislaron la bacteria Alteromonas haloplanktis con capacidad de producir una sustancia antimicrobiana capaz de inhibir tanto bacterias gram positivas como negativas, especialmente a bacterias patógenas para estas larvas, tales como Vibrios anguillarum, $V$. alginolyticus y Aeromonas hydrophila, las cuales son resistentes a diversos antibióticos. Por su parte, Araya et al. (1999), encontraron en larvas de $A$. purpuratus 11 cepas con actividad inhibitoria contra el crecimiento de $V$. anguillarum. Asimismo, Godoy et al. (2011) caracterizaron 46 cepas aisladas e identificadas mediante secuenciación del gen 16S rARN, donde $25(54 \%)$ pertenecieron a la clase Gammaproteobacteria, 11 (24\%) Bacilli, 5 (11\%) Actinobacteria, 4 (9\%) Alfaproteobacteria y 1 (2\%) Flavobacteria. Los géneros más abundantes en las muestras de agua fueron Alteromonas, Brevibacterium, Bacillus, Microbacterium y Marinobacter, mientras que, en las de larvas de A. purpuratus fueron Pseudoalteromonas, Bacillus, Marinobacterium, Alteromonas y Vibrio.

Ganesan et al. (2010) aislaron tres cepas bacterianas, Pseudoalteromonas sp, Macrococcus sp y Bacillus sp de Ulva lactuca, de mejillón (Perna canaliculus) y de alícuotas de agua de mar. A partir de ellas se construyó biofilms monoespecíficos y se ensayó la fijación de larvas de Perna canaliculus en estadio pediveliger, encontrando que el asentamiento en los biofilms de Macrococcus sp y Bacillus sp fueron significativamente mayores frente a un control sin biofilm.

El objetivo del presente estudio fue aislar, seleccionar y caracterizar genéticamente bacterianas nativas de Argopecten purpuratus que, a través de un biofilm, estimulen su asentamiento larval.

\section{Materiales y Métodos}

El estudio estuvo conformado por cuatro tratamientos, tres con bacterias y uno sin bacterias (control) con tres repeticiones por tratamiento (Cuadro 1). 
Cuadro 1. Distribución experimental de las cepas bacterianas

\begin{tabular}{ll}
\hline & Tratamientos \\
\hline $\mathrm{T}_{0}$ & Control (sin bacterias) \\
$\mathrm{T}_{1}$ & $\mathrm{C}_{1}$ : cepa Oceanobacillus \\
$\mathrm{T}_{2}$ & $\mathrm{C}_{2}$ : cepa Bacillus \\
$\mathrm{T}_{3}$ & $\mathrm{C}_{1}+\mathrm{C}_{2}$ \\
\hline
\end{tabular}

\section{Muestreo Bacteriológico}

Se suspendieron colectores comerciales de mallas de Netlon ${ }^{\circledR}$ en la Bahía de Sechura, norte del Perú, durante 15 días para tomar tres muestras de $10 \mathrm{~cm}^{2}$ de la malla y una muestra de Ulva lactuca. Las muestras se colocaron en cajas petri esterilizadas y depositadas en una caja térmica a $15^{\circ} \mathrm{C}$ para su transporte al laboratorio de bacteriología de la empresa Aquapecten Norte S.A.C., ubicada en Sechura, Piura.

\section{Aislamiento y Cultivo de Cepas Bacte- rianas}

Se utilizó la metodología propuesta por Avendaño-Herrera et al. (2002), para lo cual se colocaron las muestras en tubos falcón con $50 \mathrm{ml}$ de solución salina estéril al $0.85 \%$, agitándose hasta que se desprendió el biofilm, momento en que se retiró la malla y la $U$. lactuca. Los tubos falcón con la suspensión bacteriana fueron almacenados a $4{ }^{\circ} \mathrm{C}$.

Se hicieron diluciones seriadas de la suspensión bacteriana hasta $10^{-4}$. De cada muestra se tomó una alícuota de $100 \mu 1$ y se sembró por duplicado en placas petri con Agar Tripticasa Soya (TSA) y se incubó durante $24 \mathrm{~h}$ a $30^{\circ} \mathrm{C}$. Se contó el número de unidades formadoras de colonias por mililitro (UFC $\mathrm{ml}^{-}$ $\left.{ }^{1}\right)$ y se seleccionaron las colonias más representativas por cada placa. El criterio para la selección de cepas bacterianas fue la domi- nancia de los morfotipos crecidos en las placas; por pruebas enzimáticas (oxidasa, catalasa, proteasa) y por la taxonomía molecular. Las cepas aisladas fueron suspendidas en caldo (TSB) hasta las pruebas respectivas.

\section{Selección de Cepas}

\section{Dominancia de los morfotipos}

Cada muestra de las cepas aisladas se extendió en una lámina porta objeto y se dejó secar a temperatura ambiente, y luego se fijó con una gota de metanol; se flameó tres veces y se le colocó una gota de violeta de genciana dejando reaccionar por $1 \mathrm{~min}$, luego se enjuagó con abundante agua y se le agregó 2 gotas de lugol dejando reaccionar por $1 \mathrm{~min}$. Se adicionó dos gotas de acetona y se dejó reaccionar por $5 \mathrm{~s}$ para luego enjuagar con abundante agua. Se le agregó dos gotas de safranina dejando reaccionar por 1 min. Esta tinción mostró un color rosado rojizo para las bacterias gram negativas. La muestra se lavó con agua y se observó en un microscópico invertido a 100X con aceite de inmersión. Los criterios de selección fueron bacterias gram positivas y que presenten formas de bacilos (cocobacilos, bacilo, diplobacilo y estreptobacilo).

\section{Pruebas enzimáticas}

- Oxidasa. Se tomó una muestra de cada cepa aislada y se suspendió a un disco de papel filtro, previamente impregnado en una solución de diclorhidrato de tetrametil-p-fenilendiamina al 1\% (reactivo de Kovacs). Se consideraron positivas las que cambiaron a azul púrpura luego de $15 \mathrm{~s}$ de colocado el reactivo.

- Catalasa. A cada muestra de las cepas aisladas se les añadió 2 a 3 gotas de una solución de $\mathrm{H}_{2} \mathrm{O}_{2}$ al 3\%. Se consideraron positivas las reacciones que produjeron efervescencia.

- Proteasa. Las cepas aisladas fueron cultivadas en medio agar sólido enriquecido con leche desnatada bacteriológica 
(skim milk) al $1 \%$ como fuente proteica, e incubadas durante $72 \mathrm{~h}$ a $27^{\circ} \mathrm{C} . \mathrm{La}$ formación de un halo claro alrededor del crecimiento bacteriano se consideró $(+)$ para producción de proteasa.

\section{Identificación taxonomía molecular}

La identificación mediante taxonomía molecular de las cepas bacterianas fue a partir del análisis de las secuencias parciales del gen 16S rARN usando la técnica de PCR para el ADN extraído. Las secuencias obtenidas fueron alineadas con las secuencias de la base de datos GenBank (https://www.ncbi.nlm.nih.gov/genbank/) usando para ello el software online Nucleotide Blast (http:// blast. ncbi.nlm.nih.gov/Blast.cgi) (Zhang et al., 2000), comparándose el porcentaje de similitud existente.

\section{- Amplificación del gen $16 S$ rRNA}

Se utilizó el kit gSYNCTM DNA Extraction Kit (https://www.geneaid.com/ data/files/1605679909234517178.pdf) para amplificar el gen 16S rRNA. Para cada muestra, se adicionó en un microtubo (Eppendorf, Alemania) de $0.5 \mathrm{ml}: 31.7 \mu 1 \mathrm{de}$ agua ultrapura, $10.0 \mu 1$ de solución buffer $5 \mathrm{X}$, $4.0 \mu 1$ de $\mathrm{MgCl}_{2}, 1.0 \mu 1$ del mix de dNTP, 1.0 $\mu 1$ del iniciador 27F (5'-AGAGTTTGATCCT GGCTCAG-3') (Lane, 1991 citado por Xie et al., 2007), 1,0 $\mu 1 \mathrm{del}$ iniciador $1492 \mathrm{R}$ (5'CGGCTACCTTG TTACGACTT-3'), (Lane, 1991 citado por Xie et al., 2007), $0.3 \mu 1$ de taq polimerasa, $1.0 \mu \mathrm{l}$ del ADN bacteriano extraído. La amplificación se realizó en un termociclador Techne FTC3102D, cuya programación fue: i) Pre-desnaturalización a 95 ${ }^{\circ} \mathrm{C}$ por $5 \mathrm{~min}$; ii) 40 ciclos de las siguientes etapas: $94{ }^{\circ} \mathrm{C}$ por $30 \mathrm{~s}$ (desnaturalización), $50{ }^{\circ} \mathrm{C}$ por $45 \mathrm{~s}$ (hibridación) y $72{ }^{\circ} \mathrm{C}$ por 1 min (polimerización); y iii) polimerización final a $72{ }^{\circ} \mathrm{C}$ por $7 \mathrm{~min}$.

La verificación de la amplificación se hizo al migrar los amplicones en geles de agarosa al $2 \%$ conteniendo también $5 \mu 1$ de bromuro de etidio y como tampón de migra- ción $120 \mathrm{ml}$ de TAE $1 \mathrm{X}$ y $2 \mu 1$ de tampón de depósito y $10 \mu 1$ de cada amplicón procedentes de la PCR. La migración se realizó a 68 $\mathrm{V}$ durante $30 \mathrm{~min}$. Conjuntamente se hizo migrar un marcador de peso molecular de $1000 \mathrm{pb}$. Los geles fueron visualizados utilizando un transiluminador UVP White/UV para verificar la presencia de ADN.

\section{- Secuenciación del ADN}

Se retiró $20 \mu 1$ de los productos obtenidos de la amplificación por PCR y de los cebadores correspondientes, y se colocaron en tubos eppendorf de $0.5 \mathrm{ml}$. Las muestras fueron empacadas en hielo seco y enviados a la empresa Macrogen (https://dna.macrogen.com/eng/member/login.jsp). Los resultados de la secuenciación obtenida las cepas aisladas pasaron a la etapa de la selección.

\section{Impregnación de las Cepas Bacterianas}

Se usaron cuatro tanques de $1000 \mathrm{~L}$ de capacidad, previamente desinfectados con cloro (20\%) y llenados con $600 \mathrm{~L}$ de agua de mar filtrada a $0.5 \mu \mathrm{m}$ y esterilizada por UV. Se adicionó mediante el Medio Guillar f/2 los macronutrientes $\left(1.0 \mathrm{ml} \mathrm{L}^{-1}\right)$ y micronutrientes $\left(1.0 \mathrm{ml} \mathrm{L}^{-1}\right)$, así como las vitaminas biotina y tiamina $\left(0.5 \mathrm{ml} \mathrm{L}^{-1}\right)$, metasilicato $\left(0.5 \mathrm{ml} \mathrm{L}^{-1}\right)$ y las cepas bacterianas nativas, teniendo en cuenta los tratamientos $\mathrm{T}_{1}$ (tanque con adición de cepa 1: Oceanobacillus), $\mathrm{T}_{2}$ (tanque con adición de cepa 2: Bacillus), $\mathrm{T}_{3}(\tan -$ que con adición de cepa 1 y 2: Oceanobacillus y Bacillus) y $\mathrm{T}_{0}$ (tanque sin adición de cepas). La concentración de las cepas adicionadas fue de $1 \times 10^{4}$ células $\mathrm{ml}^{-1}$. En cada tanque se sumergieron en forma vertical 240 colectores de malla Netlon ${ }^{\circledR}$ durante 6 días. Las mallas fueron previamente desinfectadas con cloro $(20 \%)$.

\section{Preparación de los Tanques}

Se usaron 12 tanques de $10000 \mathrm{~L}$ en los que se distribuyeron los cuatro tratamientos con sus tres repeticiones. Los tanques fueron desinfectados con cloro $(20 \%)$ y se 
Cuadro 2. Caracterización, reacción a las pruebas de tinción gram y pruebas enzimáticas de las cepas bacterianas nativas aisladas de Ulva lactuca (1C-5C) y de la malla Netlon ${ }^{\circledR}(6 C-10 C)$ colectadas en la Bahía de Sechura, Piura

\begin{tabular}{|c|c|c|c|c|c|c|}
\hline Cód. & Característica & Morfotipos & $\begin{array}{l}\text { Tinción } \\
\text { gram }\end{array}$ & Oxidasa & Catalasa & Proteasa \\
\hline $1 \mathrm{C}$ & $\begin{array}{l}\text { Colonia blanca redonda } \\
\text { de } 0.3 \mathrm{~mm} \text { de diámetro }\end{array}$ & Cocobacilos & - & + & + & - \\
\hline $2 \mathrm{C}$ & $\begin{array}{l}\text { Colonia amarilla } \\
\text { redonda de } 2.5 \mathrm{~mm} \text { de } \\
\text { diámetro }\end{array}$ & Cocobacilos & - & + & + & - \\
\hline $3 \mathrm{C}$ & $\begin{array}{l}\text { Colonia irregular } \\
\text { naranja cremosa }\end{array}$ & Cocos & - & - & - & - \\
\hline $4 \mathrm{C}$ & $\begin{array}{l}\text { Colonia irregular } \\
\text { naranja }\end{array}$ & Vibrios & - & - & - & - \\
\hline $5 \mathrm{C}$ & Colonia irregular crema & Cocos & - & - & - & - \\
\hline $6 \mathrm{C}$ & $\begin{array}{l}\text { Colonia redonda crema } \\
\text { de } 1 \mathrm{~mm} \text { de diámetro }\end{array}$ & Cocobacilos & + & + & + & + \\
\hline $7 \mathrm{C}$ & $\begin{array}{l}\text { Colonia redondeada } \\
\text { blanca cremosa }\end{array}$ & Bacilos & + & + & + & + \\
\hline $8 \mathrm{C}$ & $\begin{array}{l}\text { Colonia irregular } \\
\text { naranja cremosa }\end{array}$ & Cocobacilos & - & + & + & - \\
\hline $9 \mathrm{C}$ & $\begin{array}{l}\text { Colonia irregular } \\
\text { naranja cremosa }\end{array}$ & Estreptobacilos & - & + & + & - \\
\hline $10 \mathrm{C}$ & $\begin{array}{l}\text { Colonia irregular } \\
\text { naranja intensa }\end{array}$ & Estreptobacilos & - & + & + & - \\
\hline
\end{tabular}

(+): Resultado positivo, (-): Resultado negativo

llenaron con agua de mar filtrada a $1.0 \mu \mathrm{m}$ y esterilizada por UV. Además, se les instaló una piedra difusora para dar aireación continua. Seguidamente se suspendieron 80 colectores impregnados con las cepas bacterianas aisladas, según tratamiento. A todos los tanques se les incorporó microalgas (Isochrysis galbana, Chaetoceros calcin-trans, Chaetoceros gracilis, Pavlova lutherii y Tetraselmis suecica) a concentración de 30000 células $\mathrm{ml}^{-1}$.

\section{Selección de las Larvas Competentes}

Las larvas de 22 días pos-eclosión fueron seleccionadas utilizando un tamiz de 200 $\mu \mathrm{m}$ con el que se obtuvo larvas de 225 a 280 $\mu \mathrm{m}$ de longitud anteroposterior. Las larvas seleccionadas fueron depositadas en recipientes con $3 \mathrm{~L}$ de agua de mar microfiltrada $(0.22 \mu \mathrm{m})$ y esterilizada mediante UV. Se colocó $1 \mathrm{ml}$ de la muestra en placas petri para su observación al estereoscopio, seleccionándose aquellas que mostraron características 
Cuadro 3. Identificación molecular de las cepas aisladas de Ulva lactuca y de la malla Netlon ${ }^{\circledR}$ colectadas en la Bahía de Sechura, Piura, y porcentaje de similitud con las especies

\begin{tabular}{|c|c|c|c|c|}
\hline Código. & Género & Especie & $\begin{array}{c}\text { Similitud } \\
(\%)\end{array}$ & Acceso \\
\hline \multirow[t]{2}{*}{$1 \mathrm{C}$} & Pseudomonas & Unculture pseudomana sp & 99.19 & JX841331 \\
\hline & & Pseudomonas fluorescens & 99.06 & СР032618 \\
\hline \multirow[t]{2}{*}{$2 \mathrm{C}$} & Pseudomonas & Pseudomonas azotoformans & 99.73 & MF445219 \\
\hline & & Pseudomonas fluorescens & 99.73 & MH580200 \\
\hline \multirow[t]{2}{*}{$6 \mathrm{C}$} & Oceanobacillus & Oceanobacillu sp & 99.87 & DQ358670 \\
\hline & & Oceanobacillu profundus & 99.87 & HQ595230 \\
\hline \multirow[t]{2}{*}{$7 \mathrm{C}$} & Bacillus & Bacillus sp & 88.65 & KT291172 \\
\hline & & Bacillus circulans & 87.88 & KT291130 \\
\hline \multirow[t]{2}{*}{$8 \mathrm{C}$} & Pseudomonas & Unculture pseudomanas sp & 99.87 & JX841331 \\
\hline & & Pseudomonas sp & 99.73 & GQ246655 \\
\hline \multirow[t]{2}{*}{$9 \mathrm{C}$} & Pseudomonas & Pseudomonas sp & 99.47 & EU482923 \\
\hline & & Pseudomonas fluorescens & 99.37 & LK995415 \\
\hline
\end{tabular}

de larvas competentes, según lo descrito por Tapia et al. (1993); y las características morfoló-gicas descritas por Tamburri et al. (1992). Se consideró el desplazamiento de las larvas, la presencia de mancha ocular, el tamaño de larva $(250 \mu \mathrm{m})$, la presencia y desarrollo del pie. Las larvas seleccionadas fueron depositadas en los tanques experimentales, a una concentración de 1 larva/ml.

\section{Asentamiento Larval}

Después de 72 h se sacudieron los colectores en baldes de $10 \mathrm{~L}$. Se tomó una muestra de $100 \mathrm{ml}$ en una placa petri para su conteo con la ayuda de un estereoscopio. Se determinó el número de larvas asentadas en cada uno de los colectores. Los resultados se extrapolaron al total de larvas asentadas por colector. Se consideró como larva asentada aquella que permaneció adherida al sustrato desde su traslado del tanque experimental a una placa petri para su conteo.

\section{Resultados}

Aislamiento y caracterización de las cepas bacterianas nativas

Se logró aislar 5 cepas (1C al 5C) de las muestras de Ulva lactuca y 5 cepas de la malla Netlon ${ }^{\circledR}(6 \mathrm{C}$ al $10 \mathrm{C})$, con una concentración de $1.23 \times 10^{4}$ y $2.24 \times 10^{4} \mathrm{UFC} \mathrm{ml}^{-1}$, respetivamente. Se caracterizaron cinco morfotipos (cocobacilos, cocos, vibrios, bacilos, estreptobacilos) y frente a la tinción se observó una predominancia de bacterias gram negativas, excepto las cepas 6C y 7C. En la prueba de oxidasa y catalasa las cepas $3 \mathrm{C}$, 4C y 5C tuvieron una reacción negativa, mientras que las demás cepas reaccionaron positivamente. En el caso de la prueba de proteasa solo las cepas $6 \mathrm{C}$ y $7 \mathrm{C}$ presentaron reacción positiva (Cuadro 2 ). 
Cuadro 4. Promedio de larvas de Argopecten purpuratus fijadas por colector por cada tratamiento y su respectiva repetición

\begin{tabular}{lcccc}
\hline Tratamientos & $\mathrm{R}_{1}$ & $\mathrm{R}_{2}$ & $\mathrm{R}_{3}$ & Promedio \\
\hline $\mathrm{T}_{0}$ : Sin bacterias & 8038 & 8249 & 8311 & $8199^{\mathrm{d}}$ \\
$\mathrm{T}_{1}:$ Oceanobacillus & 12362 & 11863 & 11901 & $12045^{\mathrm{c}}$ \\
$\mathrm{T}_{2}$ : Bacillus & 13442 & 13745 & 13877 & $13688^{\mathrm{b}}$ \\
$\mathrm{T}_{3}:$ Oceanobacillus + Bacillus & 37757 & 37375 & 36706 & $37279^{\mathrm{a}}$ \\
\hline
\end{tabular}

$a, b, c$ Letras diferentes indican diferencias estadísticas significativas $(p<0.05)$

Identificación molecular y selección de las cepas bacterianas nativas

De las 10 cepas bacterianas nativas aisladas, a través del programa BLAST, solo se pudo amplificar a siete de ellas, identificándose a nivel de género a tres de ellas: Pseudomonas, Oceanobacillus y Bacillus. Para el género Pseudomonas fueron las cepas $1 \mathrm{C}, 2 \mathrm{C}, 8 \mathrm{C}, 9 \mathrm{C}$ y $10 \mathrm{C}$, siendo las especies $P$. fluorescens, $P$. azotoformans, $P$. tolaasii, Pseudomonas sp y una especie no cultivable (Pseudomonas sp) (Cuadro 3). La cepa $6 \mathrm{C}$ fue identificada como parte del género Oceanobacillus con las especies Oceanobacillus sp y Oceanobacillus profundus; la cepa 7C como parte del género Bacillus, siendo las especies Bacillus sp y Bacillus circulans. Estas especies fueron seleccionadas para la fijación de larvas de $A$. purpuratus.

\section{Asentamiento larval de A. purpuratus}

El Cuadro 4 muestra el promedio del asentamiento larval de A. purpuratus para cada tratamiento. Los promedios son significativamente diferentes entre sí $(\mathrm{p}<0.05)$. La Figura 1 muestra el asentamiento larval de A. purpuratus, observándose que la combinación de ambas cepas presentó un mayor porcentaje de fijación (37\%) frente al tratamiento control $(8 \%)$.

\section{Discusión}

Las cepas bacterianas nativas aisladas del cultivo de $A$. purpuratus fueron mayormente Pseudomonas, seguido de Oceanobacillus y Bacillus, lo que se contrasta con los resultados reportados por Diringer et al. (2015) al caracterizar por metagenómica la microbiota asociada a $A$. purpuratus de la Bahía de Sechura determinando bacterias del género Pseudomonas en las vísceras y bacterias del género Bacillus en la hemolinfa; así mismo Godoy et al. (2011) encontraron bacterias del género Bacillus.

Diversos estudios han demostrado que las larvas de moluscos se asientan en respuesta a un tipo específico de biofilm; sin embargo, las bacterias pueden inhibir o incentivar la fijación de larvas de moluscos sobre un substrato (Yang et al., 2013). En este sentido se evaluó el efecto del biofilm formado por las cepas Oceanobacillus y Bacillus por separado y en combinación sobre la fijación de larvas de A. purpuratus, donde los resultados demuestran que los biofilms monoespecíficos formados por las cepas bacterianas ensayadas estimularon la fijación de larvas de A. purpuratus, a diferencia del tratamiento control sin las cepas bacterianas; sin embargo, en larvas de 


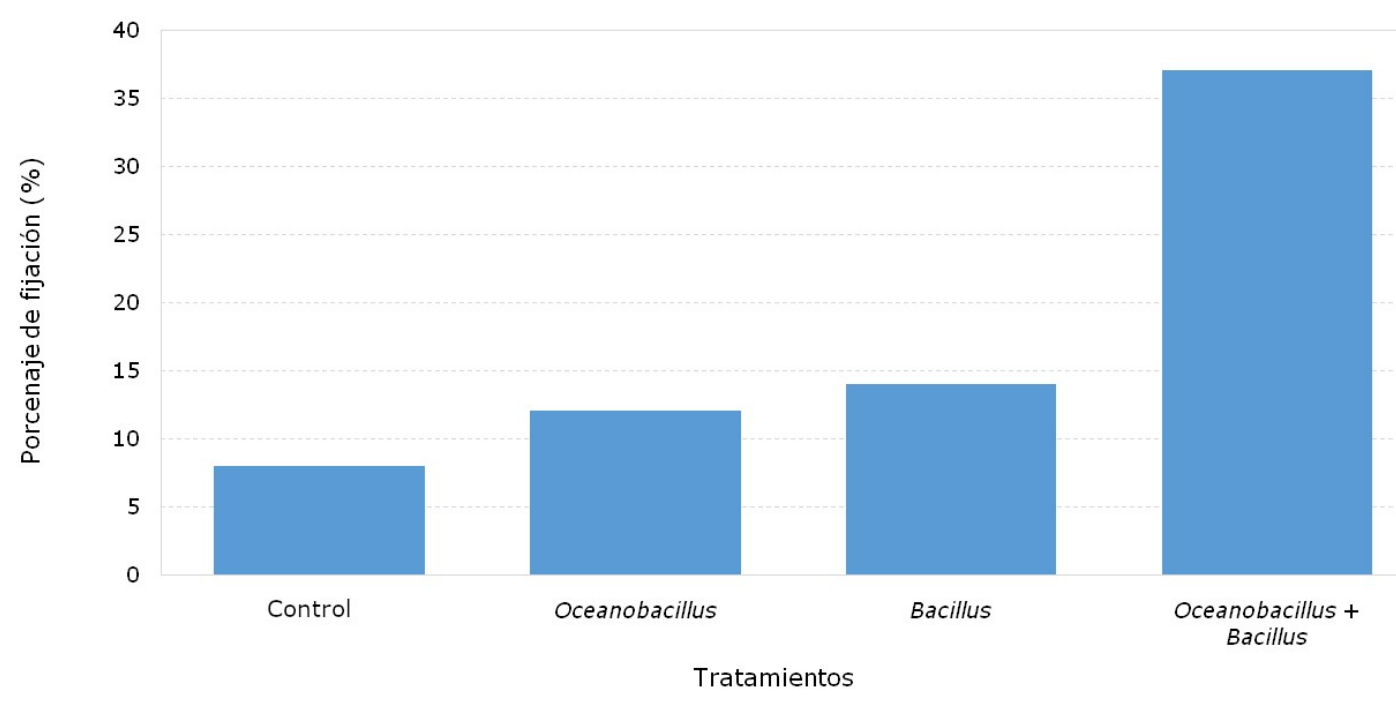

Figura 1. Porcentaje promedio de larvas de Argopecten purpuratus fijadas según tratamiento (Sin bacterias, Oceanobacillus, Bacillus, y la combinación de Oceanobacillus con Bacillus)

Balanus amphitrites pueden no tener efecto (Maki et al., 1992). En el presente estudio se demostró que los biofilms formados a partir de cepas bacterianas de Oceanobacillus y Bacillus tienen una mayor fijación (12 y $14 \%$, respectivamente) frente al tratamiento control (8\%), pero al combinar las dos cepas mejoró la capacidad de fijación en $37 \%$. En el trabajo de Ganesan et al. (2010), los biofilm formados por Pseudoalteromonas sp no indujeron la fijación, mientras que los formados por Macrococcus sp y Bacillus sp lo hicieron (50 y $60 \%$, respectivamente). Estos resultados confirman que los biofilms formados por cepas del género Bacillus ayudan en la fijación de larvas de $A$. purpuratus mejorando el asentamiento de semillas de este molusco.

\section{Conclusiones}

- Se aislaron 10 cepas bacterianas nativas de Ulva lactuca y de la malla Netlon ${ }^{\circledR}$ colectadas en la Bahía de Sechura, Piura y se pudo caracterizar a siete géneros, entre los que predominaron Pseudomonas, Oceanobacillus y Bacillus.

- Los biofilms formados a partir de cepas de Oceanobacillus y Bacillus por separado incrementaron el asentamiento larval de $A$. purpuratus en 12 y $14 \%$, respetivamente, mientras que al estar asociadas el incremento fue de $37 \%$.

\section{Literatura Citada}

1. Avendaño M, Cantillánez M. 2008. Aspectos biológicos y poblacionales de Argopecten purpuratus en la reserva marina La Rinconada: contribución para su manejo. FAO Actas de Pesca y Acuicultura 12: 249-266.

2. Araya $R$. Jorquera M. Riquelme $C$. 1999. Asociación de bacterias al ciclo de vida de Argopecten purpuratus. Rev Chil Hist Nat 72: 261-271.

3. Avendaño-Herrera R. Riquelme $C$. Silva F. 2002. Utilización de biopelículas bacterianas en el asentamiento de lar- 
vas de Argopecten purpuratus (Lamarck. 1819) en un hatchery comercial. Rev Biol Mar Oceanogr 37: 35-41.

4. Bermúdez P, Maidana J, Aquino H, Palomino A. 2004. Manual de cultivo suspendido de concha abanico. Lima, Perú: Ministerio de la Producción. 103 p.

5. Bonar D, Coon S, Walch M, Weiner R, Fitt W. 1990. Control of oyster settlement and metamorphosis by endogenous and exogenous chemical cues. B Mar Sci 46: 484-498.

6. Branda $S$, Vik A, Friedman L, Kolter R. 2005. Biofilms: the matrix revisited. Trends Microbiol 13: 20-26. doi: 10.1016/ j.tim.2004.11.006

7. Cantillánez M, Riquelme C, Avendaño M. 2010. Evaluación en ambiente natural del uso de biopeliculas marinas en el asentamiento larval de Argopecten purpuratus (Lamarck. 1819). Lat Am J Aquat Res 38: 47-56. doi: 10.3856/ vol38-issue1-fulltext-5

8. Decho $A W$. 2000. Microbial biofilms in intertidal systems: an overview. Cont Shelf Res 20: 1257-1273. doi: 10.1016/ S0278-4343(00)00022-4

9. Diringer B, Pazminio J, Lucero $C$, Pretell K, Zabala J, Zapata K, Mialhe E. 2015. Aplicación de la metagenómica para el estudio de la microbiota asociada a la concha abanico en el Perú. Repositorio Concytec. [Internet]. Disponible en: https://www.aquahoy.com/i-d-i/ genetica/32315-cientificos-estudian-elmetagenoma-de-la-concha-de-abanicode-la-bahia-de-sechura

10. Donlan RM. 2002. Biofilms: microbial life on surfaces. Emerg Infect Dis 8: 881-890. doi:10.3201/eid0809.020063

11. [FAO] Organización de las Naciones Unidas para la Alimentación y la Agricultura. 2006. Cultivo de bivalvos en criadero un manual práctico. Documento Técnico de Pesca 471: 1-184.

12. Fitt WK, Coon SL, Walch M, Weiner RM, Colwell RR, Bonar DB. 1990. Settlement behavior and metamorphosis of oyster larvae (Crassostrea gigas) in response to bacterial supernatants. Mar Biol 106: 389-394. doi:10.1007/bf01344317

13. Ganesan AM, Alfaro AC, Brooks JD, Higgin CM. 2010. The role of bacterial biofilms and exudates on the settlement of mussel (Perna canaliculus) larvae. Aquaculture 306: 388-392. doi: 10.1016/ j.aquaculture.2010.05.007

14. Godoy F, Espinoza M, Wittwer G, Uriarte I, Aranda C. 2011. Characterization of culturable bacteria in larval cultures of the Chilean scallop Argopecten purpuratus. Cienc Mar 37: 339-348. doi: $10.7773 / \mathrm{cm} . v 37 \mathrm{i} 3.1882$

15. Hadfield M. 1986. Settlement and recruitment of marine invertebrates: a perspective and some proposals. B Mar Sci 39: 418-425.

16. Maki J, Rittchof D, Mitchell R. 1992. Inhibition of larval barnacle attachment to bacterial films. An investigation of physical properties. Microb Ecol 23: 97 106. doi: 10.1007/BF00165910

17. Morse A, Morse D. 1984. Recruitment and metamorphosis of Haliotis larvae induced by molecules uniquely available at the surfaces of crustose red algae. $\mathrm{J}$ Exp Mar Biol Ecol 75: 191-215. doi: 10.1016/0022-0981(84)90166-7

18. Pazos F, Santos Y, Magariños B, Bandín I, Nuñez S, Toranzo AE. 1993. Phenotypic characteristics and virulence of Vibrio anguillarum related organisms. Appl Environ Microb 59: 2969-2976. doi: 10.1128/AEM.59.9.2969-2976.1993

19. Riquelme C, Hayashida G, Toranzo AE, Vilches J, Chávez P. 1995. Pathogenicity studies of Vibrio anguillarum related strain causing an epizootic in Argopecten purpuratus larvae cultured in Chile. Dis Aquat Organ 22: 135-141. doi: 10.3354/dao022135

20. Rodríguez SR, Ojeda FP, Inestrosa NC. 1992. Inductores químicos del asentamiento de invertebrados marinos bentónicos: importancia y necesidad de su estudio en Chile. Rev Chil Hist Nat 65: 297-310. 
21. Sutherland I. 2001. The biofilm matrixan immobilized but dynamic microbial environment. Trends Microbiol 9: 222227. doi: $10.1016 / S 0966-842 X(01)-$ 02012-1

22. Tamburri MN, Zimmer-Faust RK, Tamplin ML. 1992. Natural sources and properties of chemical inducers mediating settlement of oyster larvae: a re-examination. Biol Bull 183: 327-338. doi: $10.2307 / 1542218$

23. Tapia C, Dupré E, Bellolio G. 1993. Descripción del comportamiento de pedivelígeras de Argopecten purpuratus (Lamarck. 1819). Rev Biol Mar Oceanogr 28: 75-84.

24. Wainman B, Hincks S, Kaushik N, Mackie G. 1996. Biofilm and substrate preference in the dreissenid larvae of Lake Erie. Can J Fish Aquat Sci 53: 134140. doi: 10.1139/f95-213
25. Wolfaart G, Lawrence J, Robarts R, Caldwell S, Caldwell D. 1994. Multicellular organization in a degradative biofilm community. Appl Environ Microb 60: 434-446. doi: 10.1128/AEM.60.2.434-446.1994

26. Xie X, Xiao S, He Z, Liи J, Qіи G. 2007. Microbial populations in acid mineral bioleaching systems of Tong Shankou Copper Mine. China. J Appl Microbiol 103: 1227-1238. doi: 10.1111/ j.1365-2672.2007.03382.x

27. Yang J-L, Shen P-J, Liang X, Li Y-F, Bao W-Y, Li J-L. 2013. Larval settlement and metamorphosis of the mussel Mytilus coruscus in response to monospecific bacterial biofilms. Biofouling 29: 247-259. doi: 10.1080/ 08927014.2013.764412

28. Zhang Z, Schwartz S, Wagner L, Miller $W .2000$. A greedy algorithm for aligning DNA sequences. J Comput Biol 7: 203214. doi: $10.1089 / 1066527005-0081478$ 